\title{
Efficacy and safety of Levamisole treatment in clinical presentations of non-hospitalized patients with COVID-19: a double-blind, randomized, controlled trial
}

Amirreza Roostaei Firozabad', Zohreh Akhoundi Meybodi', Seyed Ruhollah Mousavinasab ${ }^{3}$, Adeleh Sahebnasagh ${ }^{4}$, Mohsen Gholinataj Jelodar ${ }^{5}$, Iman Karimzadeh ${ }^{6}$, Solomon Habtemariam ${ }^{7}$ and Fatemeh Saghafi ${ }^{8^{*}}$

\begin{abstract}
Background: Levamisole has shown clinical benefits in the management of COVID-19 via its immunomodulatory effect. However, the exact role of Levamisole effect in clinical status of COVID-19 patients is unknown. We aimed to evaluate the efficacy of Levamisole on clinical status of patients with COVID-19 during their course of the disease.

Methods: This prospective, double-blind, randomized controlled clinical trial was performed in adult patients with mild to moderate COVID-19 (room-air oxygen saturation > 94\%) from late April 2020 to mid-August 2020. Patients were randomly assigned to receive a 3-day course of Levamisole or placebo in combination with routine standard of care.

Results: With 25 patients in each arm, 50 patients with COVID-19 were enrolled in the study. Most of the study participants were men (60\%). On days 3 and 14, patients in Levamisole group had significantly better cough status distribution when compared to the placebo group ( $P$-value $=0.034$ and 0.005 , respectively). Moreover, there was significant differences between the two groups in dyspnea at follow-up intervals of $7(P$-value $=0.015)$ and $14(P$ value $=0.010$ ) days after receiving the interventions. However, no significant difference in fever status was observed on days $1,3,7$, and 14 in both groups ( $P$-value $>0.05$ ).

Conclusion: The results of the current study suggest that Levamisole may improve most of clinical status of patients with COVID-19. The patients receiving Levamisole had significantly better chance of clinical status including cough and dyspnea on day 14 when compared to the placebo. However, the effect-size of this finding has uncertain clinical importance.
\end{abstract}

Trial registration: The trial was registered as IRCT20190810044500N7 (19/09/2020).

Keywords: Levamisole, Hydroxychloroquine, COVID-19, SARS-CoV2, Clinical status

\footnotetext{
*Correspondence: f.saghafi@ssu.ac.ir; saghafi.fa@gmail.com

${ }^{8}$ Department of Clinical Pharmacy, Faculty of Pharmacy and Pharmaceutical

Sciences Research Center, Shahid Sadoughi University of Medical Sciences,

Yazd, Iran

Full list of author information is available at the end of the article
}

(c) The Author(s). 2021 Open Access This article is licensed under a Creative Commons Attribution 4.0 International License, which permits use, sharing, adaptation, distribution and reproduction in any medium or format, as long as you give appropriate credit to the original author(s) and the source, provide a link to the Creative Commons licence, and indicate if changes were made. The images or other third party material in this article are included in the article's Creative Commons licence, unless indicated otherwise in a credit line to the material. If material is not included in the article's Creative Commons licence and your intended use is not permitted by statutory regulation or exceeds the permitted use, you will need to obtain permission directly from the copyright holder. To view a copy of this licence, visit http://creativecommons.org/licenses/by/4.0/ The Creative Commons Public Domain Dedication waiver (http://creativecommons.org/publicdomain/zero/1.0/) applies to the data made available in this article, unless otherwise stated in a credit line to the data. 


\section{Background}

In late December 2019, a novel human coronavirus, Severe Acute Respiratory Syndrome Coronavirus 2 (SARSCoV-2 or COVID-19), was identified as the cause of a series of pneumonia cases in Wuhan, Hubei Province in China [1-3]. The outbreak has rapidly spread, resulting in an epidemic throughout China, as well as other countries around the world. On March 12th 2020, the World Health Organization (WHO) announced the outbreak of COVID-19 as a pandemic [4]. Predominant symptoms at the initiation of the disease include the following: fever, cough, myalgia, chills, dyspnea and pneumonia. Less common Symptoms are sputum, headache, hemoptysis and diarrhea [5].

Since the structure of the SARS-CoV and SARSCoV-2 was similar, the biochemical interactions and the pathogenesis were also expected to be similar [6]. However, the pathogenic mechanism may proceed differently in the novel SARS-CoV-2 and the intermediate host of SARS-CoV2 is yet to be identified. In order to enter into the host cell, the virus needs to bind to the angiotensin-converting enzyme 2 (ACE-2) receptors in the type II pneumocytes in the lungs and form a viral endosome through a clathrin-mediated endocytosis [7-9]. When internalized, the fusion of virus with lysosomes occurs under low endosomal and lysosomal pH [10]. The binding of the SARSCoV-2 to the ACE- 2 receptors triggers an inflammation cascade in the lower respiratory tract and causes a systemic inflammatory state. Infection of human cells by SARS-CoV-2 results in inflammatory cascade by virus-infected antigen-presenting cells (APCs). APCs present the outsider antigen to CD4+-T-helper (Th1) cells, and release interleukin-12 which further stimulate B-cells to produce antigen-specific antibodies [11, 12]. Currently, few approved prophylactic or therapeutic medications are available for COVID19 diseases. Some therapeutic agents are used offlabel, alone or in combination [13].

Levamisole is a synthetic low-molecular weight agent which belongs to the anti-helminthic class of medications. Levamisole can enhance cellular immunity depending on the dosage and timing of the administration $[14,15]$. In in-vitro models, it has been reported that the combination of Levamisole and ascorbic acid can reverse the depressed helper/inducer subpopulation of lymphocyte in measles virus. The abnormality in lymphocytes number could be reproduced in Levamisole treated lymphocytes in-vitro $[15,16]$.

Through improving the cellular immunity, Levamisole showed efficacy in various autoimmune and inflammatory diseases [17]. Interestingly, this anti-helminthic medication is able to phagocytose the immune cells to the normal level via its immune regulatory properties.
Furthermore, Levamisole improved the function of human interferon and modulates T-cell immunity. The efficacy of this drug has been further documented in the management of some malignancies and autoimmune diseases such as rheumatoid arthritis and systemic lupus erythematosus, vitiligo, and viral warts [18]. Levamisole inserts its promising effects on cellular and humoral immunity through regulating the circulating proinflammatory cytokines such as interleukins (IL) 6 and 8. Levamisole has also been used in patients with recurrent aphthous ulcers and it is believed to normalize the CD4 + / CD8 + cell ratio and elevates the serum levels of IgA and IgM.

Therefore, considering the pathophysiology of COVID-19 and the immunomodulatory properties of Levamisole, we conducted this double-blind, randomized controlled trial to evaluate the efficacy and safety of Levamisole when compared to the routine standard of care in non-hospitalized patients with mild to moderate COVID-19.

\section{Methods}

This prospective, double-blind, randomized controlled clinical trial was performed in adult patients aged between 18 to 60 year old with mild to moderate COVID19 (room-air oxygen saturation $>94 \%$ ) who referred to the infection clinic of Shahid Sadoughi Hospital, Yazd, Iran. The diagnosis of COVID-19 was based on the results of polymerase chain reaction (PCR) (using the realtime PCR method with Pishtazteb kit, Pishtazteb company, Iran) and radiological manifestations of COVID-19 chest computed tomography (CT) scan during a 4 month period from late April 2020 to mid-August 2020. Patients were randomly assigned into two arms of the study by permutation block method: 25 patients in the control group and 25 patients in the intervention group. This study was approved by the Ethics Committee of Yazd University of Medical Sciences (Ethics ID: IR.SSU.REC.1399.063).

\section{Exclusion and inclusion criteria}

Patients were included in the study if they met the following criteria: aged between 18 to 60 years old, diagnosis of COVID- 19 in the previous $24 \mathrm{~h}$ based on the clinical signs and symptoms and radiographical manifestations in lung CT scan, had not taken Levamisole during the previous 5 days (according to the 16-h half-life of the drug). In female patients, the eligible candidates were not being pregnant or planned pregnancy at least 30 days after the end of the study. The enrolled patients were also candidate for outpatient care and were informed not to take medications outside the study protocol. Patients were not included in this trial if they had the following criteria: hospitalization, hemodynamic 
instability, history of cirrhosis, hepatitis and severe liver diseases, severe renal failure (estimated glomerular filtration rate less than $30 \mathrm{~mL} / \mathrm{min}$ ), taking Levamisole for other indications (e.g., parasitic infections), history of allergic reaction or known allergy to Levamisole, history of receiving chemotherapy for cancer, Pregnant or lactating women.

\section{Intervention}

Patients were randomly assigned into the following arms of the study by permutation block method: Levamisole with routine standard of care or placebo with routine standard of care. Routine standard of care consisted of hydroxychloroquine $200 \mathrm{mg}$ twice daily for 5 days with acetaminophen $500 \mathrm{mg}$ tablets to manage fever and diphenhydramine syrup $10 \mathrm{cc}$ every $8 \mathrm{~h}$ for the management of cough. Patients in the intervention group took Levamisole $50 \mathrm{mg}$ orally (manufactured by Rouzdarou) three times a day for 3 days in addition to the routine stands of care. Patients in the control group received placebo (placebo tablets were prepared in the Pharmaceutics Laboratory of Shahid Sadoughi School of Pharmacy, Yazd) in addition to the routine standard of care.

\section{Measurements}

Demographic characteristics and the initial symptoms of the patients were recorded in the prepared questionnaire at baseline. Warning signs were explained to the patients for immediate referral and a pamphlet containing the contents was handed to them. Patients were contacted for follow-up visit in the clinic on the third and seventh days and were questioned about their clinical symptoms provided in the questionnaire. They were also asked about the use of acetaminophen for the management of fever, the extent of dyspnea and cough and their correlation with the level of activity, and the need for followup visit or hospitalization.

\section{Statistical analysis}

The quantitative and qualitative variables were reported as mean \pm standard deviation and number (frequency), respectively. The normally and non-normally distributed quantitative variables were compared between groups by using the independent Sample t-test and MannWhitney, respectively. Moreover, the qualitative variables were compared between two groups by using the ChiSquare test. We applied Fisher Exact test when the data sparsity was observed. All the statistical analysis was conducted by SPSS software version 20 and differences with a value of $P$-value $<0.05$ were considered significant.

\section{Results}

\section{Patients' characteristics}

Between April 12, 2020, and August 2, 2020, 59 patients with mild to moderate COVID-19 (room-air oxygen saturation $>94 \%$ ) were evaluated for eligibility. From these patients, 50 were considered eligible. 25 patients were assigned to receive Levamisole along with the routine standard of care and 25 patients to receive placebo in addition to the routine care. The mean $\pm \mathrm{SD}$ age of the patients in this study was $36.68 \pm 13.33$ years, and $60 \%$ of the patients were male. There were no significant differences in demographic characteristics between groups. Patients were balanced in baseline demographics characteristics in the two groups (Table 1).

From 59 patients who consented and were assessed for eligibility, 52 underwent randomization and initiate the study: 27 were assigned to the Levamisole/ routine care group and 25 patients continued routine care with placebo (Fig. 1). Two patients withdrew the study due to wrong number and not answer the phone for follow-up visits, and 50 patients completed the trial. A CONSORT flow diagram of the study is presented in Fig. 1.

\section{Clinical improvement during Levamisole treatment}

On days 3 and 14, patients randomized to the Levamisole/routine care group had significantly better cough status when compared with those randomized to placebo/routine care $(P$-value $=0.034$ and 0.005 , respectively). The differences in fever status on days 1 , 3,7 , and 14 between the Levamisole/routine care and placebo/routine care groups were not statistically significant $(P>$.

0.05). There were significant differences between two groups in dyspnea over a median follow-up on 7th $(P$ value $=0.015)$ and 14 th $(P$-value $=0.010)$ days after receiving the interventions which indicates a significant improvement in Levamisole/routine care group when compared to the placebo/routine care group. Individual patients' clinical improvement in the placebo/routine care group were compared with Levamisole/ routine care and presented in detail in Table 2. The parameters of headache, asthenia, dizziness, myalgia, and nausea were also assessed on days 1, 3, 7 and 14. Our findings showed no significant difference in these variables at baseline and during the treatment $(P$-value $>0.05)$. As shown in Table 3, Dyspnea was evaluated based on New York Heart Association (NYHA) classification. Only one patient needed hospitalization for 14 days, which belonged to the placebo/routine care group and all the patients survived throughout or following the treatment. No adverse effects were reported by patients in either group. 
Table 1 Patients Demographic Data

\begin{tabular}{|c|c|c|}
\hline Characteristics & Placebo/Routine Care & Levamisole/ Routine Care \\
\hline \multicolumn{3}{|l|}{ Sex, No. (\%) } \\
\hline Male & $13(52.0)$ & $17(68.0 \%)$ \\
\hline Female & $12(48.0)$ & $8(32.0 \%)$ \\
\hline \multicolumn{3}{|l|}{ Age, median (IQR), y } \\
\hline & $32.0(15)$ & $30.0(14)$ \\
\hline \multicolumn{3}{|l|}{ Weight, median (IQR), kg } \\
\hline & $70.0(18)$ & $74.0(18)$ \\
\hline \multicolumn{3}{|l|}{ Marital status, No. (\%) } \\
\hline Single & $6(24.0)$ & $6(24.0)$ \\
\hline Married & $19(76.0)$ & $19(76.0)$ \\
\hline \multicolumn{3}{|l|}{ Smoking, No. (\%) } \\
\hline Yes & $2(8.0)$ & $4(16.0)$ \\
\hline No & $23(92.0)$ & $21(84.0)$ \\
\hline \multicolumn{3}{|c|}{ Mean of room-air 02 Sats, $\%$} \\
\hline & 96.50 & 96.33 \\
\hline \multicolumn{3}{|c|}{ Lung CT-Scan involvement, No. (\%) } \\
\hline Positive & $22(88.0)$ & $22(88.0)$ \\
\hline Negative & $0(0.0)$ & $2(8.0)$ \\
\hline None & $3(12.0)$ & $1(4.0)$ \\
\hline \multicolumn{3}{|c|}{ Lung CT-Scan involvement Score, \% } \\
\hline & 2.50 & 2.75 \\
\hline \multicolumn{3}{|l|}{ PCR, No. (\%) } \\
\hline Positive & $24(96.0)$ & $22(88.0)$ \\
\hline Negative & $1(4.0)$ & $3(12.0)$ \\
\hline \multicolumn{3}{|c|}{ Coexisting conditions, No. (\%) } \\
\hline Cardiovascular disease & $1(4.0)$ & $0(0.0)$ \\
\hline Hypertension & $2(8.0)$ & $1(4.0)$ \\
\hline Diabetes & $3(12.0)$ & $1(4.0)$ \\
\hline Asthma & $0(0.0)$ & $2(8.0)$ \\
\hline Hypothyroidism & $1(4.0)$ & $0(0.0)$ \\
\hline
\end{tabular}

No Number, $y$ year, $\mathrm{kg}$ kilogram, O2 Sats oxygen saturation, CT-Scan Computed Tomography Scan, CT involvement Score Scoring the severity by the percentages of each of the five lobes that is involved: 1 for $<5 \%, 2$ for $5-25 \%, 3$ for $26-49 \%, 4$ for $50-75 \%$, and $>75 \%$ involvement. The total score is the sum of the individual lobar scores [19], $P C R$ polymerase chain reaction

As acetaminophen is the first drug of choice for fever and pain management in patients suffering from COVID-19, acetaminophen requirement was also recorded in both groups. As illustrated in Table 4, there was no significant difference between two groups in acetaminophen requirement.

\section{Discussion}

The present study was a randomized controlled clinical trial evaluating the effectiveness of Levamisole in combination with routine care in patients suffering from COVID-19. The results of the current study have demonstrated that patients receiving the combination of Levamisole with routine standard of care had significantly higher chance of better clinical status including cough and dyspnea on day 14 when compared to the placebo. However, the effect-size of this finding has uncertain clinical importance. No significant difference in fever, headache, asthenia, dizziness, myalgia, and nausea was observed on days $1,3,7$, and 14 between groups.

Currently, the coronavirus COVID-19 pandemic is a global dilemma. Since the main pathogenic mechanism of the disease is unclear, many drugs have been 


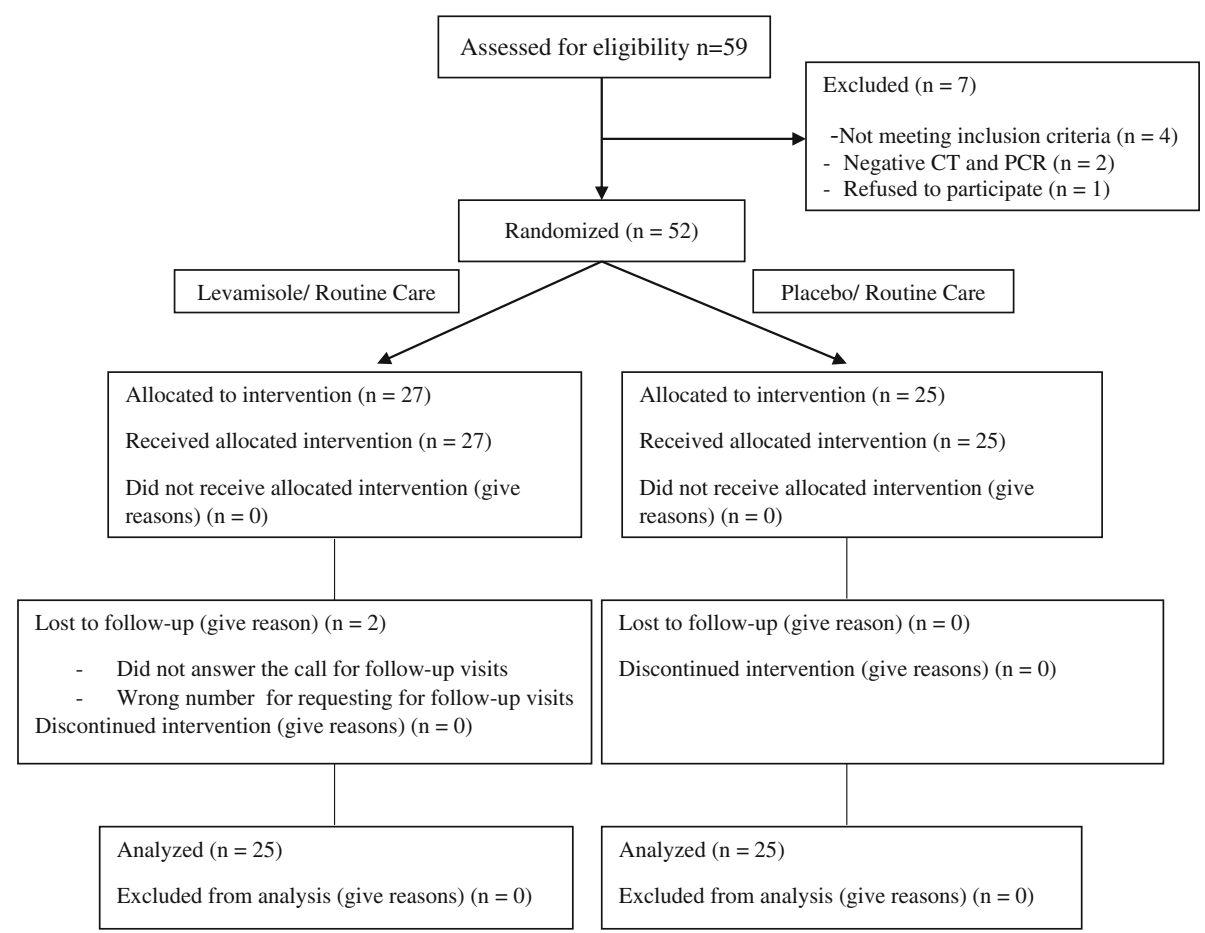

Fig. 1 CONSORT flow diagram

evaluated in an attempt to relieve the symptoms [21]. One of the suggestive agents used for systemic treatment of COVID-19 is Levamisole because of its wide variety of immunological effects including regulation of neutrophils, macrophages, and T-cell activity. Moreover, this drug also modulates the human interferon (IFNs), interleukin-6 (IL-6) and IL-8 [22, 23] and enhances the serum level of immunoglobulin A (IgA) and IgM [24]. The combination of Levamisole with ascorbic acid has shown to reverse the depressed helper/inducer subpopulation of lymphocyte in an invitro study. In vitro observations have further shown that the abnormality in lymphocytes could be reproduced in Levamisole-treated lymphocytes. Therefore, Levamisole could be suggested for the treatment of COVID-19 [23, 25].

As with the previous study in China [14], more than half of the infected patients in the current study were men (60\%). The most common clinical presentations of 41 infected patients with COVID-19 in Wuhan, China, were the following: fever $(98.0 \%)$, cough (76.0\%), dyspnea (55.0\%), myalgia (44.0\%), sputum production (28.0\%), headache (8.0\%), hemoptysis (5\%), and diarrhea (3\%) [14]. The most common clinical presentations in the current study were fever (88.0\%), cough (78.0\%), and dyspnea (54.0\%). While less common symptoms were asthenia (18.0\%), headache (8.0\%), dizziness $(6.0 \%)$, myalgia $(6.0 \%)$, and nausea $(6.0 \%)$ at the initiation of the trial. Nevertheless, no significant difference between groups were observed.

Pro-inflammatory state is the second phase of COVID-19 disease and commonly associated with elevation in several inflammatory cytokines including IL-6 and IL-8 that results in acute lung injury, cytokine storm and systemic inflammation [15]. Thus, inflammatory response reduction could be considered as a potential therapeutic target against COVID-19 disease in this phase. Several studies are currently underway to elucidate the potential molecular mechanisms and employ some interventions to suppress this phase of COVID-19 $[15,16]$. Heretofore, no specific antiviral treatment is available for COVID-19. While accurate information about the effectiveness of different lmmunomodulators are limited, anti-inflammatory and immunomodulatory therapies has the potential for COVID-19 patients in the pro-inflammatory phase [16].

In severe cases of COVID-19, the plasma level of IL-6 is especially high [26]. Using Tocilizumab (TCZ), a human IL-6 blockade agent, indicated a reduction in lung lesion opacity, oxygen demand, decrease in C-reactive protein, and normalization of lymphocytes count in 90.5, $75,84.2$, and $52.6 \%$ in COVID-19 patients, respectively [27]. Levamisole is another anti-IL-6 agent. This drug blocks pro-inflammatory activity of IL- 6 and could be effective in the management of COVID-19 patients.

Although the findings of the present study are interesting, care should be taken in implementing these 
Table 2 The Most Common Patients' Clinical Status on Study Days 1, 3, 7, and 14

\begin{tabular}{|c|c|c|c|}
\hline \multirow[t]{2}{*}{ Clinical Presentation } & \multirow{2}{*}{$\begin{array}{l}\text { Placebo/Routine Care } \\
\text { N (\%) }\end{array}$} & \multirow{2}{*}{$\begin{array}{l}\text { Levamisole/ Routine Care } \\
\text { N (\%) }\end{array}$} & \multirow[t]{2}{*}{$P$ value } \\
\hline & & & \\
\hline \multicolumn{4}{|l|}{ Fever } \\
\hline Day 1 & $20(80.0)$ & $24(96.0)$ & 0.189 \\
\hline Day 3 & $20(80.0)$ & $24(96.0)$ & 0.189 \\
\hline Day 7 & $3(12.0)$ & $0(0.0)$ & 0.235 \\
\hline Day 14 & $0(0.0)$ & $0(0.0)$ & 1.000 \\
\hline \multicolumn{4}{|l|}{ Cough } \\
\hline Day 1 & $17(68.0)$ & $22(88.0)$ & 0.088 \\
\hline Day 3 & $17(68.0)$ & $23(92.0)$ & 0.034 \\
\hline Day 7 & $17(68.0)$ & $15(60.0)$ & 0.556 \\
\hline Day 14 & $9(36.0)$ & $1(4.0)$ & 0.005 \\
\hline \multicolumn{4}{|l|}{ Dyspnea } \\
\hline Day 1 & $13(52.0)$ & $14(56.0)$ & 0.777 \\
\hline Day 3 & $13(52.0)$ & $14(56.0)$ & 0.777 \\
\hline Day 7 & $12(48.0)$ & $4(16.0)$ & 0.015 \\
\hline Day 14 & $0(0.0)$ & $7(28.0)$ & 0.010 \\
\hline \multicolumn{4}{|l|}{ Asthenia } \\
\hline Day 1 & $5(20.0)$ & $4(16.0)$ & 0.490 \\
\hline Day 3 & $5(20.0)$ & $2(8.0)$ & 0.235 \\
\hline Day 7 & $4(16.0)$ & $1(4.0)$ & 0.235 \\
\hline Day 14 & $3(12.0)$ & $0(0.0)$ & 0.235 \\
\hline \multicolumn{4}{|l|}{ Headache } \\
\hline Day 1 & $2(8.0)$ & $2(8.0)$ & 1.000 \\
\hline Day 3 & $2(8.0)$ & $2(8.0)$ & 1.000 \\
\hline Day 7 & $1(4.0)$ & $0(0.0)$ & 1.000 \\
\hline Day 14 & $1(4.0)$ & $0(0.0)$ & 1.000 \\
\hline \multicolumn{4}{|l|}{ Dizziness } \\
\hline Day 1 & $2(8.0)$ & $1(4.0)$ & 1.000 \\
\hline Day 3 & $2(8.0)$ & $1(4.0)$ & 1.000 \\
\hline Day 7 & $2(8.0)$ & $0(0.0)$ & 0.490 \\
\hline Day 14 & $2(8.0)$ & $0(0.0)$ & 0.490 \\
\hline \multicolumn{4}{|l|}{ Myalgia } \\
\hline Day 1 & $3(12.0)$ & $2(8.0)$ & 0.235 \\
\hline Day 3 & $3(12.0)$ & $2(8.0)$ & 0.235 \\
\hline Day 7 & $3(12.0)$ & $0(0.0)$ & 0.235 \\
\hline Day 14 & $2(8.0)$ & $0(0.0)$ & 0.490 \\
\hline \multicolumn{4}{|l|}{ Nausea } \\
\hline Day 1 & $2(8.0)$ & $1(4.0)$ & 1.000 \\
\hline Day 3 & $2(8.0)$ & $1(4.0)$ & 1.000 \\
\hline Day 7 & $1(4.0)$ & $1(4.0)$ & 1.000 \\
\hline Day 14 & $1(4.0)$ & $0(0.0)$ & 1.000 \\
\hline
\end{tabular}

results and the limitations of the study should be considered. First, the main limitation was the small size of the subject groups. It should be pointed out that until now; the efficacy of Levamisole in COVID-19 management has not been evaluated. Thus, this primary evaluation is the first trial of Levamisole to gain an insight for future 
Table 3 Dyspnea Evaluation Based on NYHA classification on Study Days 1 and 14

\begin{tabular}{|c|c|c|c|c|}
\hline \multirow[t]{3}{*}{ NYHA Class } & \multicolumn{2}{|c|}{$\begin{array}{l}\text { Placebo/Routine } \\
\text { Care }\end{array}$} & \multicolumn{2}{|c|}{$\begin{array}{l}\text { Levamisole/ Routine } \\
\text { Care }\end{array}$} \\
\hline & Day 1 & Day 14 & Day 1 & Day 14 \\
\hline & N (\%) & & N (\%) & \\
\hline Class I (Mild) & 12 & 0 & 11 & 0 \\
\hline Class II (Mild) & 0 & 0 & 0 & 0 \\
\hline Class III (Moderate) & 8 & 4 & 8 & 0 \\
\hline Class IV (Severe) & 5 & 3 & 6 & 0 \\
\hline
\end{tabular}

Class I: No limitation of physical activity; Class II: Slight limitation of physical activity; Class III: Marked limitation of physical activity; Class IV: Unable to carry on any physical activity without discomfort [20]

studies. Second, because of the urgent circumstances in which the study was done, the effect of Levamisole on SARS-CoV-2 viral load were not assessed. Third, while the dose of Levamisole was chosen based on previous data, the effective dose for COVID is yet to be determined. The last limitation is that other laboratory variables which could be used in identifying additional predictors of patients' outcomes were not collected.

Given the small sample and the lack of power to detect an efficacy outcome difference, we cautiously interpret these data to suggest the possibility of a beneficial effect and the absence of harm. Thus, we conclude that further efficacy evaluation in the form of a larger clinical trial is warranted.

\section{Conclusions}

Previous investigation found that lmmunomodulators play an important role in management of patients infected with COVID-19 [21, 28]. Levamisole is a safe and successful immunomodulatory drug, suggesting that it may also attenuate the exaggerated immune response associated with COVID-19 severity. Our results indicated that Levamisole can efficiently improve some of the Clinical Status when compared to placebo.

Table 4 Acetaminophen Requirement in Patients Suffering with COVID-19

\begin{tabular}{llll}
\hline $\begin{array}{l}\text { Dose of } \\
\text { Acetaminophen }\end{array}$ & HCQ / placebo & HCQ / Levamisole & Total \\
\hline Yes & $12(48.0)$ & N (\%) & N (\%) \\
\hline $500 \mathrm{mg}$ tds for 2 days & $1(4.0)$ & $0(0.0)$ & $22(44.0)$ \\
$500 \mathrm{mg}$ tds for 3 days & $3(12.0)$ & $8(32.0)$ & $1(2.0)$ \\
$500 \mathrm{mg}$ tds for 8 days & $1(4.0)$ & $0(0.0)$ & $11(22.0)$ \\
$500 \mathrm{mg}$ tds for 10 days & $1(4.0)$ & $0(0.0)$ & $1(2.0)$ \\
$500 \mathrm{mg}$ tds for a week & $5(20.0)$ & $2(8.0)$ & $1(2.0)$ \\
$500 \mathrm{mg}$ tds for 2 weeks & $1(4.0)$ & $0(0.0)$ & $7(14.0)$ \\
No & $13(52.0)$ & $15(60.0)$ & $1(2.0)$ \\
\hline
\end{tabular}

The results of the current study have demonstrated that adding Levamisole to the routine standard of care significantly enhanced the overall clinical status including cough and dyspnea in COVID-19 patients when compared to the placebo/routine care. However, the effect-size of this finding has uncertain clinical importance.

\section{Abbreviations}

SARS-CoV-2 or COVID-19: Severe Acute Respiratory Syndrome Coronavirus 2; WHO: World Health Organization; ACE-2: Angiotensin-converting enzyme 2; Th1: $\mathrm{CD}_{4}{ }^{+}$-T-helper; LPV/r: Lopinavir/ritonavir; NSAIDs: Nonsteroidal antiinflammatory drugs; CQ: Chloroquine; HCQ: Hydroxychloroquine; IL6: Interleukin-6; IFNs: Human interferon; IgA: Immunoglobulin A; IgM: Immunoglobulin M; CONSORT: Consolidated Standards of Reporting Trials; NYHA: New York Heart Association; IL: Interleukins; TCZ: Tocilizumab

\section{Acknowledgements}

This article is derived from the thesis "Evaluation of Levamisole efficacy and safety in combination with routine therapy in patients with Covid-19: a clinical trial" supervised by Assistant Professor Fatemeh Saghafi and submitted by Dr. Fatemeh Saghafi to the Faculty of Pharmacy of Shahid Sadoughi University of Medical Sciences, Yazd, Iran, in partial fulfillment of the Requirements for Doctor of Pharmacy (Phar.D.) degree.

\section{Authors' contributions}

F.S., Z.A.M., S.R.M. and I.K. were involved in conception and design of the study. A.R., M.G. J., and Z.A.M. collected the data. F.S., A.R., A.S., and S.R.M. analysis the data and drafted the first manuscript. The following co-author, S. $H_{\text {., }}$ an English citizen and speaker, have edited the whole manuscript, as is detectable in the main manuscript with activated track changes. All authors read and approved the final manuscript.

\section{Funding}

The manuscript was financially supported by a grant from the Research and Technology Department of Shahid Sadoughi University of Medical Sciences (grant no. 7705), Yazd, Iran.

Availability of data and materials

All data generated or analyzed during this study are included in this published article.

\section{Declarations}

Ethics approval and consent to participate

All patients signed an informed consent form prior to participation in the study. All methods were carried out in accordance with relevant guidelines and regulations. This study was approved by the Ethics Committee of Yazd University of Medical Sciences (Ethics ID: IR.SSU.REC.1399.063). This study was also approved in the Iranian Registry of Clinical Trials (IRCT20190810044500N7) at the date of 19/09/2020.

\section{Consent for publication}

Consent for publication was agreed upon in the written consent forms signed by the patients.

\section{Competing interests}

The authors declare that they have no competing interests regarding the publication of this paper.

\section{Author details}

${ }^{1}$ Pharmaceutical Sciences Research Center, Student Research Committee, School of Pharmacy, Shahid Sadoughi University of Medical Sciences and Health Services, Yazd, Iran. ${ }^{2}$ Infectious disease research center, Shahid Sadoughi hospital, Shahid Sadoughi University of Medical Sciences, Yazd, Iran. ${ }^{3}$ Resident of Clinical Pharmacy, Department of Clinical Pharmacy, School of Pharmacy, Shiraz University of Medical Sciences, Shiraz, Iran. ${ }^{4}$ Clinical Research Center, Department of Internal Medicine, School of Medicine, North Khorasan University of Medical Sciences, Bojnurd, Iran. ${ }^{5}$ Department of 
Internal Medicine, School of Medicine, Shahid Sadoughi University of Medical Sciences, Yazd, Iran. ${ }^{6}$ Department of Clinical Pharmacy, School of Pharmacy, Shiraz University of Medical Sciences, Shiraz, Iran. ${ }^{7}$ Pharmacognosy Research Laboratories and Herbal Analysis Services UK, University of Greenwich, Central Avenue, Chatham-Maritime, Kent ME4 4TB, UK. ${ }^{8}$ Department of Clinical Pharmacy, Faculty of Pharmacy and Pharmaceutical Sciences Research Center, Shahid Sadoughi University of Medical Sciences, Yazd, Iran.

Received: 5 December 2020 Accepted: 10 March 2021

Published online: 24 March 2021

\section{References}

1. Phelan AL, Katz R, Gostin LO. The novel coronavirus originating in Wuhan, China: challenges for global health governance. JAMA. 2020;323(8):709-10. https://doi.org/10.1001/jama.2020.1097.

2. Wu Y, Ho W, Huang Y, Jin D-Y, Li S, Liu S-L, Liu X, Qiu J, Sang Y, Wang Q, Yuen KY, Zheng ZM. SARS-CoV-2 is an appropriate name for the new coronavirus. Lancet. 2020;395(10228):949-50. https://doi.org/10.1016/S01406736(20)30557-2.

3. Sahebnasagh A, Saghafi F, Safdari M, Khataminia M, Sadremomtaz A, Ghaleno HR, et al. Neutrophil Elastase inhibitor (Sivelestat), may be a promising therapeutic option for Management of Acute Lung Injury/acute respiratory distress syndrome or disseminated intravascular coagulation in COVID-19. Authorea Preprints. 2020.

4. Gautret P, Lagier J-C, Parola P, Meddeb L, Mailhe M, Doudier B, et al. Hydroxychloroquine and azithromycin as a treatment of COVID-19: results of an open-label non-randomized clinical trial. Int J Antimicrob Agents. 2020;105949:1-7.

5. Wang D, Hu B, Hu C, Zhu F, Liu X, Zhang J, Wang B, Xiang H, Cheng Z, Xiong Y, Zhao Y, Li Y, Wang X, Peng Z. Clinical characteristics of 138 hospitalized patients with 2019 novel coronavirus-infected pneumonia in Wuhan, China. JAMA. 2020;323(11):1061-9. https://doi.org/10.1001/jama.202 0.1585 .

6. Rabi FA, Al Zoubi MS, Kasasbeh GA, Salameh DM, Al-Nasser AD. SARS-CoV-2 and coronavirus disease 2019: what we know so far. Pathogens. 2020;9(3): 231. https://doi.org/10.3390/pathogens9030231.

7. Burkard C, Verheije MH, Wicht O, van Kasteren Sl, van Kuppeveld FJ, Haagmans BL, Pelkmans L, Rottier PJM, Bosch BJ, de Haan CAM. Coronavirus cell entry occurs through the endo-/lysosomal pathway in a proteolysisdependent manner. PLoS Pathog. 2014;10(11):e1004502. https://doi.org/1 0.1371/journal.ppat.1004502.

8. Gallagher T, Escarmis C, Buchmeier M. Alteration of the pH dependence of coronavirus-induced cell fusion: effect of mutations in the spike glycoprotein. J Virol. 1991;65(4):1916-28. https://doi.org/10.1128/JVI.65.4.191 6-1928.1991.

9. Blau DM, Holmes KV. Human coronavirus HCoV-229E enters susceptible cells via the endocytic pathway. The Nidoviruses: Springer; 2001. p. 193-8.

10. Ding N, Zhao K, Lan Y, Li Z, Lv X, Su J, et al. Induction of atypical autophagy by porcine hemagglutinating encephalomyelitis virus contributes to viral replication. Front Cell Infect Microbiol. 2017;7:56.

11. Kuba K, Imai Y, Rao S, Gao H, Guo F, Guan B, Huan Y, Yang P, Zhang Y, Deng W, Bao L, Zhang B, Liu G, Wang Z, Chappell M, Liu Y, Zheng D, Leibbrandt A, Wada T, Slutsky AS, Liu D, Qin C, Jiang C, Penninger JM. A crucial role of angiotensin converting enzyme 2 (ACE2) in SARS coronavirus-induced lung injury. Nat Med. 2005;11(8):875-9. https://doi. org/10.1038/nm1267.

12. Sahebnasagh A, Mojtahedzadeh M, Najmeddin F, Najafi A, Safdari M, Ghaleno HR, et al. A perspective on erythropoietin as a potential adjuvant therapy for acute lung injury/acute respiratory distress syndrome in patients with covid-19. Arch Med Res. 2020;51(7):631-5. https://doi.org/10.1016/j.a rcmed.2020.08.002.

13. Shaghaghi N. Molecular docking study of novel COVID-19 protease with low risk terpenoides compounds of plants. ChemRxiv, DOI. 2020;10.

14. Huang C, Wang Y, Li X, Ren L, Zhao J, Hu Y, Zhang L, Fan G, Xu J, Gu X, Cheng Z, Yu T, Xia J, Wei Y, Wu W, Xie X, Yin W, Li H, Liu M, Xiao Y, Gao H, Guo L, Xie J, Wang G, Jiang R, Gao Z, Jin Q, Wang J, Cao B. Clinical features of patients infected with 2019 novel coronavirus in Wuhan, China. Lancet. 2020;395(10223):497-506. https://doi.org/10.1016/50140-6736(20)30183-5.

15. Lee C, Choi WJ. Overview of COVID-19 inflammatory pathogenesis from the therapeutic perspective. Arch Pharm Res. 2021:1-18.
16. Alijotas-Reig J, Esteve-Valverde E, Belizna C, Selva-O'Callaghan A, Pardos-Gea J, Quintana A, et al. Immunomodulatory therapy for the management of severe COVID-19. Beyond the anti-viral therapy: a comprehensive review. Autoimmun Rev. 2020;102569.

17. Sharma S, Ali FM, Saraf K, Mudhol A. Anti-helminthic drugs in recurrent apthous stomatitis: a short review. J Pharm Bioallied Sci. 2014;6(2):65-8. https://doi.org/10.4103/0975-7406.129169.

18. Won TH, Park SY, Kim BS, Seo PS, Park SD. Levamisole monotherapy for oral lichen planus. Ann Dermatol. 2009;21(3):250-4. https://doi.org/10.5021/ad.2 009.21.3.250.

19. Pan F, Ye T, Sun P, Gui S, Liang B, Li L, Zheng D, Wang J, Hesketh RL, Yang $L$, Zheng $C$. Time course of lung changes at chest $C T$ during recovery from coronavirus disease 2019 (COVID-19). Radiology. 2020;295(3):715-21. https:// doi.org/10.1148/radiol.2020200370.

20. Zhang R, Ma S, Shanahan L, Munroe J, Horn S, Speedie S. Discovering and identifying New York heart association classification from electronic health records. BMC Med Inform Decis Mak. 2018;18(2):5-13.

21. Sahebnasagh A, Avan R, Saghafi F, Mojtahedzadeh M, Sadremomtaz A, Arasteh O, et al. Pharmacological treatments of COVID-19. Pharmacol Rep. 2020:1-33.

22. Renoux G. The general immunopharmacology of levamisole. Drugs. 1980; 20(2):89-99. https://doi.org/10.2165/00003495-198020020-00001.

23. Joffe M, Sukha N, Rabson A. Lymphocyte subsets in measles. Depressed helper/inducer subpopulation reversed by in vitro treatment with levamisole and ascorbic acid. J Clin Invest. 1983;72(3):971-80. https://doi. org/10.1172/JCl111069.

24. Chamani G, Rad M, Zarei MR, Hashemimanesh SR, Abbaszadeh E, Sadeghi M. Effect of levamisole on treatment of recurrent aphthous stomatitis: a systematic review and meta-analysis. J Oral Health Oral Epidemiol. 2016;5(2): 70-7.

25. Rosenthal M, Trabert U, Müller W. The effect of Levamisole on peripheral blood lymphocyte subpopulations in patients with rheumatoid arthritis and ankylosing spondylitis. Clin Exp Immunol. 1976;25(3):493-6.

26. Zhang H, Zhou P, Wei Y, Yue H, Wang Y, Hu M, Zhang S, Cao T, Yang C, Li M, Guo G, Chen X, Chen Y, Lei M, Liu H, Zhao J, Peng P, Wang CY, du R. Histopathologic changes and SARS-CoV-2 immunostaining in the lung of a patient with COVID-19. Ann Intern Med. 2020;172(9):629-32. https://doi. org/10.7326/M20-0533.

27. Xu X, Han M, Li T, Sun W, Wang D, Fu B, Zhou Y, Zheng X, Yang Y, Li X, Zhang X, Pan A, Wei H. Effective treatment of severe COVID-19 patients with tocilizumab. Proc Natl Acad Sci. 2020;117(20):10970-5. https://doi.org/1 $0.1073 /$ pnas.2005615117.

28. Zhang L, Liu Y. Potential interventions for novel coronavirus in China: a systematic review. J Med Virol. 2020.

\section{Publisher's Note}

Springer Nature remains neutral with regard to jurisdictional claims in published maps and institutional affiliations.

\section{Ready to submit your research? Choose BMC and benefit from:}

- fast, convenient online submission

- thorough peer review by experienced researchers in your field

- rapid publication on acceptance

- support for research data, including large and complex data types

- gold Open Access which fosters wider collaboration and increased citations

- maximum visibility for your research: over $100 \mathrm{M}$ website views per year

At $\mathrm{BMC}$, research is always in progress.

Learn more biomedcentral.com/submissions 